\title{
Digestion dans l'intestin grêle chez le porc 3. - Ginétique du passage de l'amidon et de l'azote au niveau iléal selon le mode de fistulation, la nature de l'amidon et le taux de protéines de l'aliment
}

\author{
Béatrice DARCY, J. P. LAPLACE et P. A. VILIIERS
}

avec la collaboration technique de Brigitte MOURơ, Georgette FrEDOU, A. ROGER

\author{
Laboratoive de Physiologie de la Nutrition \\ Centre national de Recherches Zootechniques, I.N.R.A., \\ 78350 Jouy-en-Josas (France)
}

\begin{abstract}
Résumé
Six porcs mâles castrés de race Large White d'un poids vif compris entre 47 et $64 \mathrm{~kg}$, ont été utilisés pour une étude comparative du passage de l'amidon et des matières azotées à la fin de l'intestin grêle, selon la technique de fistulation mise en œuvre : iléo-caecale vs iléo-colique postvalvulaire. Ils ont reçu un seul repas quotidien d'un aliment semi-synthétique à base d'amidon purifié (maïs ou blé, $70 \mathrm{p}$. Ioo de la M.S.) et de farine de poisson ( 6 6, 8 ou o p. roo de matières azotées totales - MAT -). Les digesta dérivés ont été recueillis toutes les 2 heures, 24 heures sur 24 et occasionnellement toutes les heures entre $9 \mathrm{~h}$ et $18 \mathrm{~h}$. On a mesuré les quantités de MAT $(\mathrm{N} \times 6,25)$ et celles d'amiđon, défini comme l'ensemble du glucose et de ses dérivés $\alpha$, dans les digesta collectés.

En plus des particularités précédemment rapportées (DARCY, LAPLACE et VILLIERS, 1980) on enregistre, dans le cas de régimes pauvres en protéines, des différences liées à la technique de fistulation telles que : débit maximum de M.A.T. plus tardif et débit maximum d'amidon à la fois plus faible et plus tardif lors de dérivation post-valvulaire. On constate par ailleurs que la digestibilité apparente plus faible des M.A.T. pour les régimes pauvres en protéines est vérifiée lors de dérivation iléale mais ne l'est pas lors de dérivation post-valvulaire. L'influence de la nature de l'amidon sur la digestion des M.A.'T. n'est détectée que lors de dérivation post-valvulaire.

Indépendamment de ces aspects liés à la technique, il apparaît que : (i) la quantité d'azote endogène produite en $24 \mathrm{~h}$ peut être estimée à $70 \mathrm{~g}$ au moins; (ii) la digestibilité de l'amidon de blé est supérieure à celle de l'amidon de maïs; (iii) la digestibilité de l'amidon est abaissée d'environ $5 \mathrm{p}$. roo dans le cas d'un régime protéiprive.
\end{abstract}

\section{Introduction}

Une nouvelle technique, dite de fistulation iléo-colique post-valvulaire, a été récemment proposée (DARCY, LAPLACE et VILLIERS, I980) pour collecter les digesta tels qu'ils sont normalement émis vers le gros intestin. Par rapport à la dérivation 
iléale des digesta, la préservation du rôle fonctionnel du sphincter iléo-caecocolique lors de dérivation post-valvulaire conduit à une estimation sensiblement différente de la cinétique de passage des digesta de l'intestin grêle vers le gros intestin. En effet, il faut environ 60 à $90 \mathrm{mn}$ de plus avant de recueillir les premiers matériaux provenant du repas d'épreuve, lors de collecte post-valvulaire. Ce délai correspond au temps de séjour des digesta dans 1'iléon du fait de la présence du sphincter iléo-caeco-colique, comme cela a été démontré indirectement par cinéradiographie ou scintigraphie chez 1'Homme et chez le Rat (WRIGHT, I952; JIAN et al., i979; Derblom, Johansson et Nylander, I966; Purdon et Bass, I973). Cette observation constitue une pretuve directe $d u$ rôle fonctionnel du sphincter iléo-caeco-colique chez le Porc.

Cette différence d'estimation de la vitesse de passage des digesta, selon le site de dérivation, s'accompagne d'une réduction importante des quantités de matière fraîche et de matière sèche collectées en $6 \mathrm{~h}$, d'un tiers et un quart respectivement, lors de dérivation post-valvulaire. Parallèlement la teneur en matière sèche des effluents collectés par fistulation iléo-colique post-valvulaire est significativement plus importante lorsque le séjour iléal des digesta a été plus long. La question se pose donc de savoir s'il existe d'autres différences qualitatives entre les digesta obtenus par dérivation iléale et ceux obtenus par la technique de dérivation post-valvulaire qui fournit des données plus proches de la réalité physiologique.

L'importance d'une évaluation correcte de l'état d'avancement de la digestion à l'extrémité distale de l'intestin grêle est considérable. Il s'agit d'établir la digestibilité partielle de chaque constituant de l'aliment au terme de la digestion enzymatique qui se déroule dans l'intestin grêle. Il s'agit aussi de connaître le rythme d'arrivée, la nature et la quantité des matériaux qui seront soumis à la digestion microbienne dans le gros intestin. La digestion enzymatique fournit en effet, chez un monogastrique tel que le Porc, l'essentiel des apports énergétique et azoté. La mesure de la digestibilité au niveau de la jonction iléo-caeco-colique devrait constituer une base plus exacte que la digestibilité fécale (prenant en compte les transformations liées à l'activité de la flore), pour raisonner la formulation des aliments du porc. Encore faut-il éviter les erreurs d'ordre méthodologique. Aussi le présent travail a-t-il pour but 1'évaluation comparative, respectivement par les techniques de fistulation iléo-caecale et de fistulation iléo-colique postvalvulaire, $(i)$ de la digestion de l'amidon de deux céréales (blé et maïs) largement employées dans l'alimentation du porc, (ii) de la digestion des matières azotées apportées sous la forme conventionnelle d'une farine de poisson, et (iii) de l'éven-. tuelle influence du taux azoté sur la digestion dans l'intestin grêle des amidons de maïs ou de blé.

\section{Matériel et méthodes}

Les résultats exposés ici sont fondés sur l'analyse des échantillons recueillis chez les mêmes animaux et selon le même protocole que précédemment (DARCy, LAPLACE et VILLIERS, I980). Cependant sont concernés dans le cas présent seulement six des neuf porcs mâles castrés de race Large White : les porcs A, B et C soumis à fistulation iléo-colique post-valvulaire et pesant respectivement 58,62 et $59 \mathrm{~kg}$; les porcs $\mathrm{M}, \mathrm{N}$ et $\mathrm{O}$ soumis à fistulation iléocaecale et pesant respectivement 64,47 et $59 \mathrm{~kg}$. Les techniques chirurgicales et les modalités de collecte des 
digesta en ballon de caoutchouc ont été détaillées dans le précédent article (DARCY, LAPLACE et VILLIERS, I980). Tous ces porcs ont été maintenus en situation de vacuité colique pendant la durée des expérimentations (non-restitution des digesta collectés).

\section{I. - Alimentation des porcs}

Les régimes expérimentaux ont été distribués en un seul repas quotidien, le matin à $9 \mathrm{~h}$. Ce sont dans tous les cas des aliments semi-synthétiques, présentés aux porcs sous forme de farine additionnée de 2 fois son poids d'eau. La majorité des enregistrements a été réalisée avec des aliments contenant I6 p. Ioo de matières azotées $(\mathrm{N} \times 6,25)$ par rapport à la matière sèche $(\mathrm{MS})$ et composés d'amidon purifié de maïs ou de blé, de farine de poisson, de cellulose purifiée et de complément minéral et vitaminique (respectivement $70,20,6$ et $4 \mathrm{p}$. Ioo de la MS). Dans un nombre plus limité de cas, des aliments ajustés à un taux de matières azotées de 8 ou de o p. I oo par substitution d'amidon à la farine de poisson ont été utilisés soit après 3 jours d'accoutumance (cas des régimes à 8 p. Ioo) soit sans accoutumance préalable (régimes protéiprives).

\section{2. - Collecte et échantillonnage des digesta}

Au cours des nycthémères expérimentaux, plusieurs chronologies de collecte ont été mises en œuvre. Chez les porcs A et M, les digesta ont été recueillis toutes les heures de 9 à $\mathrm{I} 8 \mathrm{~h}$, puis une seule fois entre $\mathrm{I} 8 \mathrm{~h}$ et $9 \mathrm{~h}$ le lendemain. Chez les porcs $\mathrm{B}, \mathrm{C}, \mathrm{N}$ et $\mathrm{O}$, les digesta ont été recueillis toutes les $2 \mathrm{~h}, 24 \mathrm{~h}$ sur 24 . Après enregistrement de leur volume et de leur poids frais, pour chaque période de collecte, les digesta ont été homogénéisés par agitation vigoureuse. Une fraction de poids constant ( $80 \mathrm{~g}$ de matière fraîche environ) a été utilisée pour la détermination de la teneur en matière sèche après lyophilisation et passage à l'étuve à $\mathrm{IO}^{\circ}{ }^{\circ} \mathrm{C}$ pendant $24 \mathrm{~h}$, et pour la mesure de la teneur en amidon et en azote.

\section{3. - Méthodes analytiques et mode d'expression des résultats}

L'azote total a été déterminé par la méthode KJELDAHL. L'amidon et ses dérivés, définis comme le glucose et tous ses polymères $\alpha$, ont été dosés selon CuBER et LAPLACE (I979). Par commodité cet ensemble de 1'amidon et de ses dérivés est désigné dans le texte sous le vocable " amidon ". On peut calculer les quantités totales de matières azotées $(\mathrm{N} \times 6,25)$ et d'amidon présentes dans la matière sèche des digesta recueillis.

Les quantités de matières azotées totales et d'amidon ainsi déterminées sont exprimées selon les cas, sous forme brute (masse en $g$ ) ou en valeur relative (p. Ioo des quantités ingérées ou $\mathrm{p}$. Ioo de la quantité de matière sèche recueillie). Pour l'expression graphique des résultats, les symboles suivants ont été uniformément utilisés : cercles (régimes à I6 p. Ioo de matières azotées), triangles (régimes à 8 p. roo) et carrés (régimes à o p. roo). Ces différents symboles sont selon les cas pleins (fistulation iléo-colique post-valvulaire) ou creux (fistulation iléo-caecale). Enfin, ils sont reliés entre eux soit par un trait continu (moyennes indépendantes de la nature de l'amidon), soit par des tirets-points alternés (régimes à base d'amidon 
de blé), soit encore par des pointillés (régimes à base d'amidon de maïs). Enfin, dans tous les graphiques ne figure que la moitié des écarts-types de la moyenne pour éviter toute confusion par superposition. Pour certains points moyens des cinétiques 1'absence de représentation de cet écart-type tient à son amplitude très faible, en deçà de la définition autorisée par le graphique.

\section{Résultats}

\section{I. - Digestion des matières azotées totales (M.A.T.)}

a) Cinétique de passage des M.A.T. (régimes à I6 p. Ioo de M.A.T.)

Les quantités de M.A.T. parvenant à la fin de l'intestin grêle varient de façon sensiblement analogue à la suite d'un repas d'épreuve, quel que soit le mode de collecte des digesta (fig. I). Ces quantités augmentent au cours des troisième et quatrième heures après le repas, pour atteindre un débit par période de $2 \mathrm{~h}$ maximum aux cinquième-sixième heures, et revenir aux valeurs initiales au-delà de la seizième heure. Le débit basal de M.A.T. est toujours inférieur à $\mathbf{I} g$ par $2 \mathrm{~h}$ et le débit maximum est de l'ordre de $5 \mathrm{~g}$ par $2 \mathrm{~h}$.

L,es bilans à la sixième et à la vingt-quatrième heure post-prandiale, exprimant

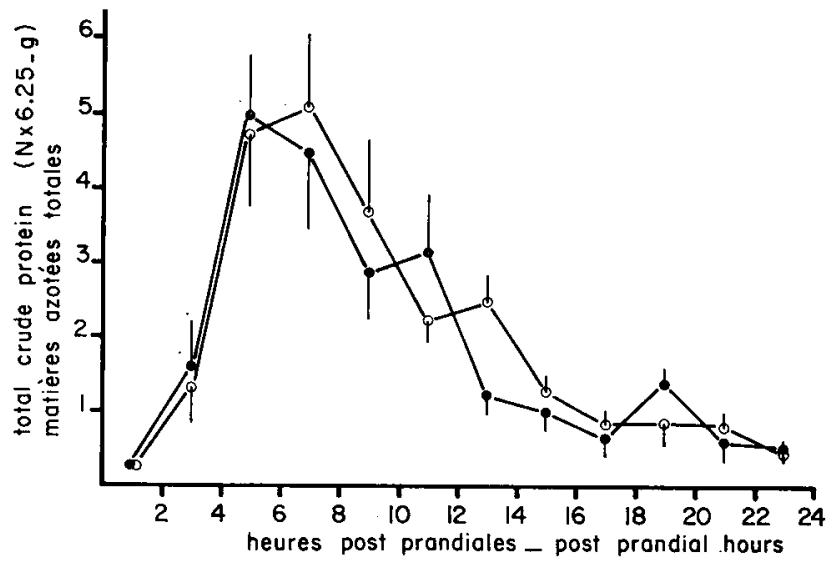

FIG. I. - Quantités moyennes de matières azotées totales collectées par période de 2 h au cours des $24 h$ consécutives à un vepas d'éprewve ingéré à $9 \mathrm{~h}$. Cinétiques représentatives de 2 porcs et 3 nycthémères par porc $(n=6)$ pour un régime à I6 p. Ioo de matières azotées totales, indépendamment de la natuve de l'amidon entrant dans la composition de l'aliment, lors de dérivation postvaluulaive (DPV, - — - chez les porcs $B$ et $C$ et lors de dérivation iléale $(D I, 0-O)$ chez les pores $N$ et $O$. L'ingévé moyen de matière sèche est de $859,9 \pm I 5, I$ $(D P V)$ et $877,7 \pm 3, I g(D I)$. L'ingévé moyen de matières azotées totales est de $137,7 \pm 2,4$ $(D P V)$ et $I 40,5 \pm 0,5 \mathrm{~g}(D I)$.

Mean amounts of crude protein collected per 2 -hr period during 24 hours following a test meal eaten at $9.00 \mathrm{a} . \mathrm{m}$. Kinetics representative of 2 pigs and $324^{-h r-c y c l e s}$ per pig $(n=6)$ for a I6 p. Ioo crude protein diet independent of the type of starch used in the diet during postvalvular collection (DPV, - — ) in pigs $B$ and $C$ and during ileal collection $(D I, 0-0)$ in pigs $N$ and $O$. Mean intake of dry matter $859.9 \pm I 5 . I g(D P V)$ and $877.7 \pm 3 . I g(D I)$; mean intake of crude protein $137.7 \pm 2.4 \mathrm{~g}(D P V)$ and $140.5 \pm 0.5 \mathrm{~g}(D I)$. 
les M.A.T. collectées en pourcentage des M.A.T. ingérées, montrent 1'absence de toute différence significative entre les estimations fournies par les deux modes de dérivation quel que soit l'amidon entrant dans la composition du régime (tab1. I comparaisons $I, 2$ et 3 ).

\section{TABLEAU I}

Quantités cumulees de matières azotées totales recueillies en 6 ou 24 h après le repas d'éprenve et exprimées en p. Ioo des quantités de matières azotées ingévées. Résultats compares selon le site de dérivation, postvalvulaire $(D P V)$ ou iléale $(D I)$, selon la nature de l'amidon ingéré, maüs ou blé, et selon le taux de matières azotées (MAT) du régime (I6 ou 8 p. Ioo). Dans chaque cas, sont indiqués la moyenne et l'écart-type de la moyenne, avec entre parenthèses le nombre de données concernées. La signification statistique éventuelle pour chacune des comparaisons (Test de $T$ de Student) est exprimée comme suit: ${ }^{*} p<0,0 I-{ }^{*} p<0,05,-(0, I O) p<0$, Io.

Cumulated quantities of total crude protein collected during 6 or 24 hours after the test meal, as per cent of the crude protein intake. Comparisons according to the site of digesta collection, either post valvular $(D P V)$ or ileal $(D I)$, according to the kind of stavch ingested, maize or wheat, and according to the dietary crude protein (MAT) level (I6 or 8 per cent). In each case, the mean and standard deviation of the mean are given, with the number of data concerned in brackets. The eventual statistical significance for each comparison (Student's $T$ test) is expressed as follows: ** $p<0.01-* p<0.05-($ o.IO) $p<0.10$.

\begin{tabular}{|c|c|c|c|}
\hline \multirow{2}{*}{$\begin{array}{c}\text { Comparaison } \\
\text { Comparison }\end{array}$} & \multirow{2}{*}{$\begin{array}{l}\text { Situation } \\
\text { Situation }\end{array}$} & \multicolumn{2}{|c|}{$\begin{array}{l}\text { Quantités cumulées de MAT collectées } \\
\text { en p. Ioo des MAT ingérées } \\
\text { (Cumulated quantities of } M A T \text { collected, } \\
\text { as per cent of } M A T \text { ingested) }\end{array}$} \\
\hline & & $\begin{array}{l}\text { Bilan à la sixième heure } \\
\text { postprandiale } \\
\text { (at the 6th postprandial hour) }\end{array}$ & $\begin{array}{l}\text { Bilan à la vingt-qnatrième } \\
\text { heure postprandiale } \\
\text { (at the 24th postprandial } \\
\text { hour) }\end{array}$ \\
\hline 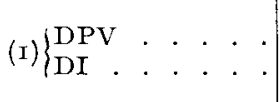 & $\begin{array}{l}\text { I6 p. Ioo MAT. } \\
\text { amidons confon- } \\
\text { dus (all stavches) }\end{array}$ & $\begin{array}{l}4,70 \pm 0,50(n=10) \\
4,63 \pm 0,44 \quad(n=10)\end{array}$ & 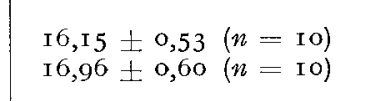 \\
\hline 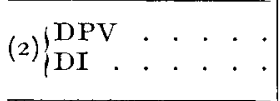 & $\begin{array}{l}\text { amidon de blé } \\
\text { (wheat starch) } \\
\text { I6 p. xoo MAT. }\end{array}$ & $\begin{array}{r}5,88 \pm 0,4^{8}(n=5) \\
(0, T O, \\
4,58 \pm 0,35(n=5)\end{array}$ & $\begin{array}{l}\text { I } 7,05 \pm 0,45(n= \\
\text { I } 6,51 \pm 0,44(n=\end{array}$ \\
\hline 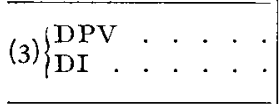 & $\begin{array}{l}\text { amidon de mais } \\
\text { (maize starch) } \\
\text { 16 p. Ioo MAT. }\end{array}$ & $\begin{array}{l}3,52 \pm 0,46(n=5) \\
3,83 \pm 0,27(n=4)\end{array}$ & $\begin{array}{l}15,25 \pm 0,80(n=5) \\
16,30 \pm 0,49(n=4)\end{array}$ \\
\hline (4) $\left\{\begin{array}{rrrr}\text { I6 } & \text { p. } & \text { I } 00 & \text { MAT } \\
8 & \text { p. } & \text { IOO } & \text { MAT }\end{array} \mid\right.$ & $\begin{array}{l}\text { DPV } \cdot \cdot \cdot \cdot \\
\text { amidons confon- } \\
\text { dus (all stanches) }\end{array}$ & $\begin{array}{l}4,70 \pm 0,50(n=10) \\
3,5^{8} \pm 0,85(n=3)\end{array}$ & $\begin{array}{l}\text { I6,I5 土0,53 }(n=\mathrm{I} 0) \\
\mathrm{I} 6,28 \pm \mathrm{I}, \mathrm{I} 7 \quad(n=3)\end{array}$ \\
\hline 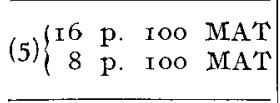 & $\begin{array}{l}\text { DI } \\
\text { amidons confon- } \\
\text { dus (all starches) }\end{array}$ & $\begin{array}{l}4,25 \pm 0,25(n=9) \\
5,61 \pm 0,64(n=3)^{*}\end{array}$ & $\begin{array}{l}\text { I } 6,42 \pm 0,3 \mathrm{I}(n=9) \\
\text { I } 8,75 \pm 0,88(n=3)^{* *}\end{array}$ \\
\hline (6) $\left\{\begin{array}{lr}\text { amidon de blé } \\
(w h e a t & \text { starch) } \\
\text { amidon de maìs } \\
\text { (maize } & \text { starch) }\end{array}\right.$ & $\begin{array}{l}\text { DPV . . . . } \\
\text { I6 }\end{array}$ & $\begin{array}{l}5,88 \pm 0,48(n=5) \\
3,5^{2} \pm 0,46(n=5)^{* *}\end{array}$ & $\begin{array}{l}\text { I 7,05 士0,45 (n= } 5) \\
\text { I5,25 士0,80 (n= } 5)\end{array}$ \\
\hline (7) $\left\{\begin{array}{l}\text { amidon de blé } \\
\text { (wheat } \text { starch }) \\
\text { amidon de mais } \\
\text { (maize starch) }\end{array}\right.$ & DI $\quad$ i & $\begin{array}{l}4,58 \pm 0,35(n=5) \\
3,83 \pm 0,27(n=4)\end{array}$ & $\begin{array}{l}16,51 \pm 0,44(n=5) \\
16,30 \pm 0,49(n=4)\end{array}$ \\
\hline
\end{tabular}


b) Influence du taux de M.A.T. du régime (I6-8-o p. Ioo)

Par rapport à la cinétique de passage observée pour un régime à $x 6 \mathrm{p}$. Ioo de M.A.T. on n'enregistre pas de différence chronologique pour des régimes à 8 ou o p. Ioo de M.A.T., lors de dérivation iléale (fig. 2A). Par contre, lors de dérivation

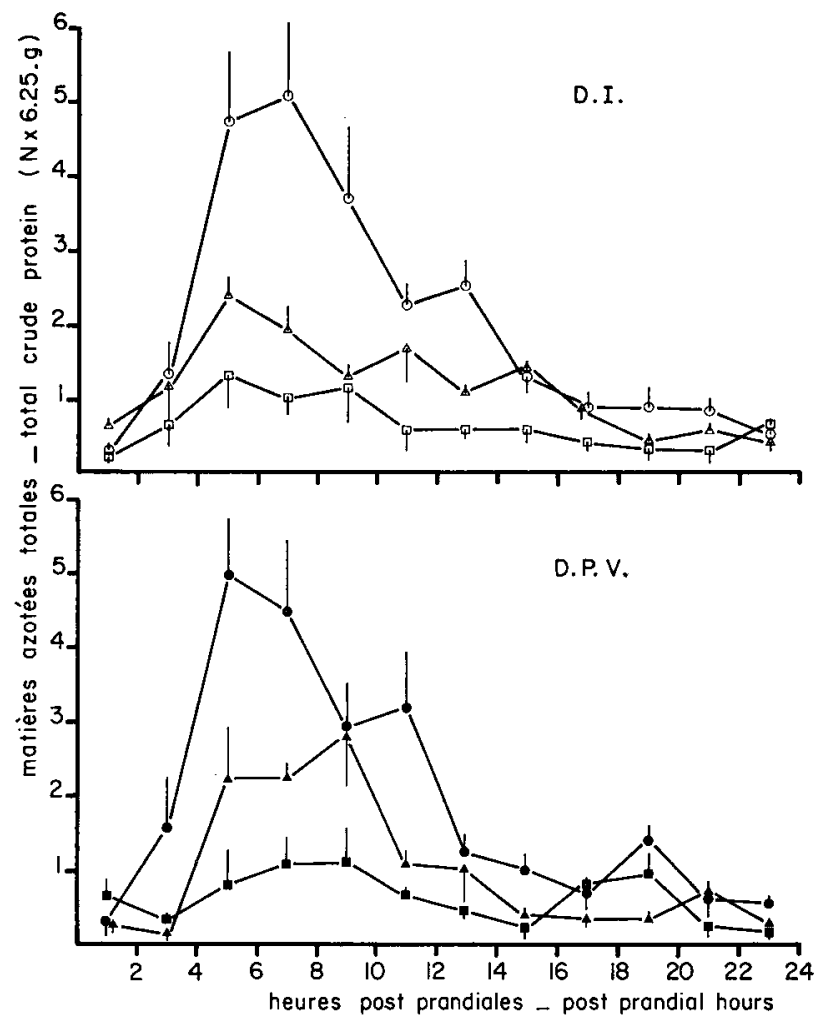

FIG. 2. - Quantités moyennes de matières azotées totales collectées par période de 2 h au cours des 24 consécutives à un repas d'épreuve ingéré à 9 h, selon le taux de matières azotées du régime. $D . I$. : Lors de dérivation iléale.

- Cinétique représentative de 2 porcs et 3 nycthémères $(n=6)$ chez les porcs $\mathrm{N}$ et $\mathrm{O}$ recevant un régime à $16 \mathrm{p}$. roo de matières azotées (o_— o). Les ingérés de matière sèche et matières azotées sont ceux indiqués dans la figure I (DI).

- Cinétique représentative de 3 nycthémères chez le porc $O$ recevant un régime à $8 \mathrm{p}$. roo de matières azotées $(\Delta-\Delta)$. Ingéré moyen de matière sèche $888,5 \pm$ o g; de matières azotées $7 \mathrm{I}, \mathrm{I} \pm \mathrm{o} \mathrm{g}$.

Cinétique représentative de 5 nycthémères chez les porcs $\mathrm{N}$ et $\mathrm{O}$ recevant un régime protéiprive ( $\mathrm{J}-\mathrm{D}$ ). Ingéré moyen de matière sèche $868, \mathrm{I} \pm 6,4 \mathrm{~g}$.

D.P.V.: Lors de dérivation post-valvulaire.

-- Cinétique représentative de 2 porcs et 3 nycthémères $(n=6)$ chez les porcs $B$ et $C$ rece-

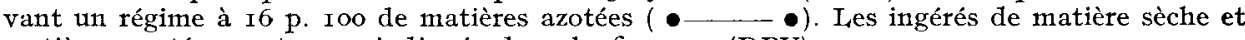
matières azotées sont ceux indiqués dans la figure I (DPV).

- Cinétique représentative de 3 nycthémères chez le porc $B$ recevant un régime à 8 p. Ioo de matières azotées (^- Ingéré moyen de matière sèche $885 \pm \circ \mathrm{g}$; de matières azotées $70,8 \pm$ o $\mathrm{g}$.

- Cinétique représentative de 5 nycthémères chez les porcs B et $\mathrm{C}$ recevant un régime protéiprive (a- - Ingéré moyen de matière sèche $75 \mathrm{I}, \mathrm{I} \pm 84,5 \mathrm{~g}$. 


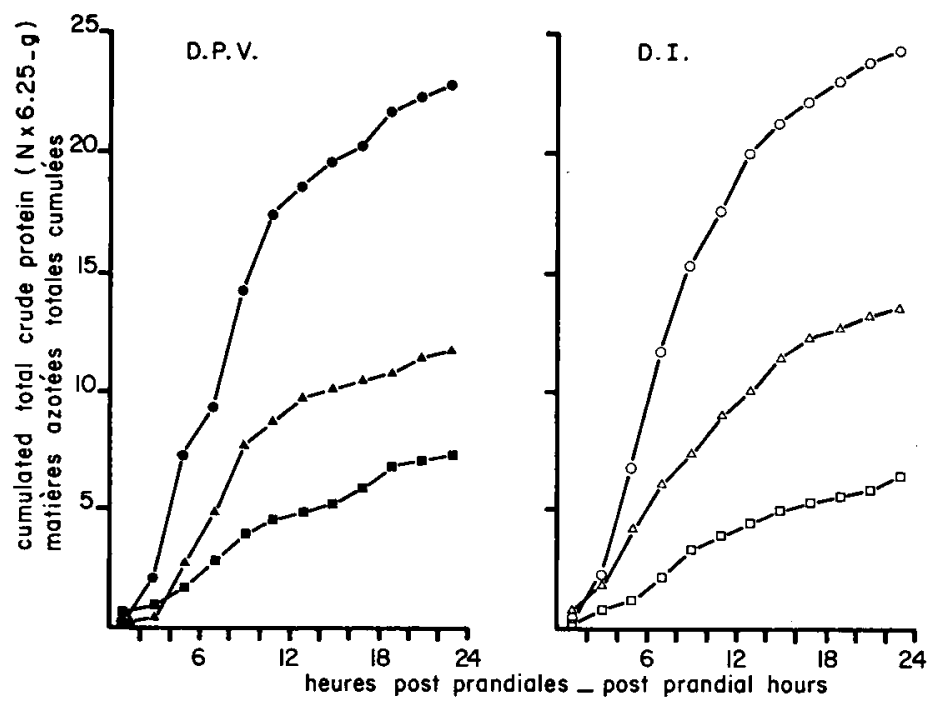

FIG. 3. - Évolution moyenne au cours des 24 h post-prandiales des quantités cumulées de matières azotées totales $(M A T)$ selon le taux de matières azotées du régime, lors de dérivation post-valvulaire $(D P V)$ et lors de dérivation iléale $(D I)$.

Mean postprandial variations (for $24 \mathrm{hr}$ ) in cumulated amounts of crude protein (MAT) according to the dietary crude protein level, in the case of post-valvular collection (DPV) or ileal collection $(D I)$.

16 p. IOO MAT :

8 p. I оo MAT:

o p. Iоo MAT :
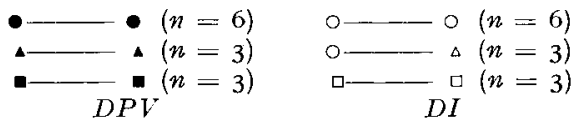

post-valvulaire, l'augmentation de la quantité de M.A.T. recueillie survient plus tard $\left(5^{\mathrm{e}}-6^{\mathrm{e}} \mathrm{h}\right)$ et le débit maximum n'est atteint qu'à la neuvième heure environ pour ces mêmes régimes à 8 ou o p. Ioo (fig. $2 \mathrm{~B}$ ).

Le débit maximum de M.A.T. par période de $2 \mathrm{~h}$ reste toujours inférieur à $3 \mathrm{~g}$

Mean amounts of crude protein collected per $2-h \mathrm{r}$ period during $24 \mathrm{hr}$ following a test meal eaten at 9.00 a.m., according to the dietary crude protein level.

D.I. : Ileal collection.

- Kinetics representative of 2 pigs and 324 -hr-cycles $(\mathrm{n}=6)$ in pigs $N$ and $O$ fed a I6 p. IOo crude protein diet ( $\mathrm{O}-\mathrm{O})$. The intake of dry matter and crude protein was the same as in figure $I(D I)$.

- Kinetics vepresentative of 324 -hr-cycles in pig o ted a 8 p. Ioo crude protein diet $(\Delta$

Mean intake of dry matter $888.5+o \mathrm{~g}$; of crude protein $75.1 \pm 0 \mathrm{~g}$.

- Kinetics representative of five 24 -hr-cycles in pigs $N$ and $O$ fed a protein-free diet

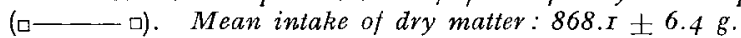

DPV: postvalvular collection

- Kinetics representative of 2 pigs and $324^{-h r-c y c l e s}(\mathrm{n}=6)$ in pigs $B$ and $C$ fed a $\mathrm{I} 6$ p. Ioo crude protein diet (•-— - The intake of dry matter and crude protein was the same as in figure $I(D P V)$.

- Kinetics representative of 324 -hr-cycles in pig $B$ fed a 8 p. Ioo crude protein diet (৯-4). Mean intake of dry matter: $885 \pm 0 \mathrm{~g}$; of crude protein: $70.8 \pm 0 \mathrm{~g}$.

- Kinetics representative of 524 -hr-cycles in pigs $B$ and C fed a protein-free diet (- Mean intake of dry matter $75 I . I \pm 84.5 \mathrm{~g}$. 
pour un régime à $8 \mathrm{p}$. Ioo de M.A.T'. et inférieur à $I, 5 \mathrm{~g}$ pour un régime à o $\mathrm{p}$. Ioo de M.A.T. Il en résulte que les quantités totales de M.A.T. parvenant à l'extrémité distale de l'intestin grêle dans les $24 \mathrm{~h}$ qui suivent un repas d'épreuve (850 g de M.S.) sont de l'ordre de $23 \mathrm{~g}$ pour un régime à $\mathrm{x} 6 \mathrm{p}$. Ioo de M.A.T., de I2 $\mathrm{g}$ pour un régime à $8 \mathrm{p}$. Ioo de M.A.T. et de $7 \mathrm{~g}$ seulement pour un régime protéiprive (fig. 3 ).

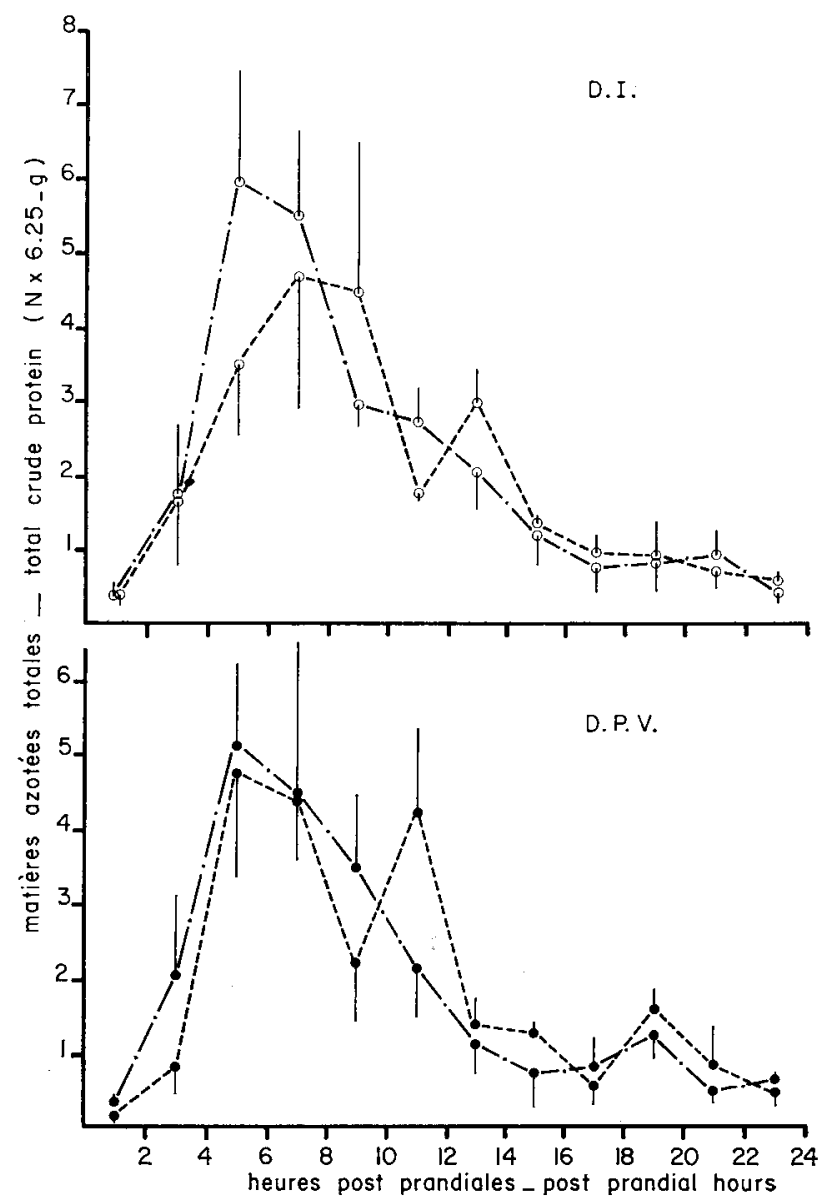

FrG. 4. - Quantités moyennes de matières azotées totales collectées par période de 2 h au cours des $24 h$ consécutives à un repas d'épreuve ingéré à 9 h, selon la nature de l'amidon d'un régime à r6 p. roo de matières azotées.

$D I$ : Lors de dérivation iléale.

- Cinétique représentative de 3 nycthémères chez le porc $\mathrm{N}$ recevant le régime à base d'amidon de blé $0--$ - o). Ingéré moyen : de matière sèche $88 \mathrm{r}, \mathrm{I} \pm 5,9 \mathrm{~g}$; de matières azotées $\mathrm{I} 4 \mathrm{I}, \mathrm{I} \pm 0,9 \mathrm{~g}$.

- Cinétique représentative de 3 nycthémères chez le porc $O$ recevant le régime à base d'amidon de maïs ( $0 \ldots-(-)$ ). Ingéré moyen : de matière sèche $874,2 \pm 0 \mathrm{~g}$; de matières azotées $139,9 \pm 0 \mathrm{~g}$.

$D P V$ : Lors de dérivation post-valvulaire.

- Cinétique représentative de 3 nycthémères chez le porc $B$ recevant le régime à base d'amidon de blé $(\bullet--\bullet)$. Ingéré moyen : de matière sèche $833,8 \pm 20,5 \mathrm{~g}$; de matières azotées r $33,5 \pm 3,3 \mathrm{~g}$.

- Cinétique représentative de 3 nycthémères chez le porc $\mathrm{C}$ recevant le régime à base d'ami- 
Pour un même niveau d'ingestion et un même taux azoté du régime, les quantités totales de M.A.T. recueillies par dérivation post-valvulaire et par dérivation iléale ne diffèrent pas significativement.

Les quantités de M.A.T. recueillies en $6 \mathrm{~h}$ ou en $24 \mathrm{~h}$ après le repas, exprimées en $\mathrm{p}$. Ioo de 1'ingéré, s'avèrent analogues pour les régimes à I 6 et $8 \mathrm{p}$. roo de M.A.T. lors de dérivation post-valvulaire (tabl. I - comparaison 4). Par contre, selon ce même mode d'expression, les quantités recueillies en 6 ou $24 \mathrm{~h}$ par dérivation iléale sont significativement plus importantes pour un régime à 8 p. roo que pour un régime à $\mathbf{6}$ p. Ioo de M.A.T. (tabl. I - comparaison 5).

\section{c) Influence de la nature de l'amidon (maïs ou blé)}

Dans le cas d'un régime à $\mathbf{r} 6$ p. roo de M.A.T. la cinétique de passage enregistrée à l'extrémité distale de l'intestin grêle, selon la nature de l'amidon ingéré (fig. 4) répond à la description générale présentée précédemment : augmentation du débit de M.A.T. au cours des troisième-quatrième heures, et retour aux valeurs initiales au-delà de la seizième heure. Le débit maximum de M.A.T. par période de 2 h est toujours observé alentour de la sixième heure sauf dans le cas d'ingestion d'amidon de maïs avec dérivation iléale des digesta (fig. $4 \mathrm{~A}$ ). Un aspect biphasique avec un second maximum autour de la douzième heure n'est observé que pour les régimes à base d'amidon de maìs quelle que soit la technique de dérivation.

Le calcul des quantités totales de M.A.T. présentes dans les digesta recueillis au cours des $24 \mathrm{~h}$ consécutives à un repas de $850 \mathrm{~g}$ de M.S. fournit, pour un même taux de M.A.T. du régime, des valeurs non significativement différentes selon la nature de l'amidon ingéré, soit 23 , I2 et $7 \mathrm{~g}$ environ, respectivement pour des régimes à $I 6,8$ et o p. Ioo de M.A.T.

Les quantités de M.A.T. récoltées en $6 \mathrm{~h}$ ou en $24 \mathrm{~h}$ après le repas, exprimées en p. Ioo de l'ingéré, s'avèrent analogues, quelle que soit la nature de l'amidon ingéré lors de dérivation iléale (tabl. I - comparaison 7). Lors de dérivation postvalvulaire, le pourcentage des M.A.T. ingérées récupéré en $6 \mathrm{~h}$ est plus élevé dans le cas de l'amidon de blé que dans le cas de l'amidon de maîs (tabl. I — comparaison 6).

don de maïs ( - - - - • ). Ingéré moyen : de matière sèche $886, \mathrm{I} \pm 5,9 \mathrm{~g}$; de matières azotées $I_{4} \mathrm{I}, 8 \pm \mathrm{I}, \mathrm{O} \mathrm{g}$.

Mean amounts of crude protein collected per 2 -hr period during $24 \mathrm{hr}$ following a test meal eaten at $9.00 \mathrm{am}$. according to the type of starch in a $r 6 \mathrm{p}$. $100 \mathrm{crude}$ protein diet.

$\mathrm{DI}$ : ileal collection.

- Kinetics representative of 324 -hr-cycles in pig $N$ fed the wheat starch diet (o- - - o).

Mean intake of dry matter $88 \mathrm{I} . \mathrm{I} \pm 5.9 \mathrm{~g}$; of cruae protein $I 4 \mathrm{I} . \mathrm{I} \pm 0.9 \mathrm{~g}$.

- Kinetics representative of 324 -hr-cycles in pig O fed the maize starch diet ( $0 . . . .0)$.

Mean intake of dry matter $874.2 \pm 0 \mathrm{~g}$; of crude proteirl $139.9 \pm 0 \mathrm{~g}$.

DPV postvalvular collection.

-- Kinetics representative of 324 -hr-cycles in pig $B$ fed the wheat starch diet ( $\bullet-\cdots)$ -

Mean intake of dry matter $833.8 \pm 20.5 \mathrm{~g}$; of crude protein $133.5 \pm 3.3 \mathrm{~g}$.

- Kinetics representative of $324-h r$-cycles in pig C fed the maize starch diet ( - . . - ).

Mean intake of dry matter 886.I $\pm 5.9 \mathrm{~g}$; of crude protein $I 4 I .8 \pm I .0 \mathrm{~g}$. 


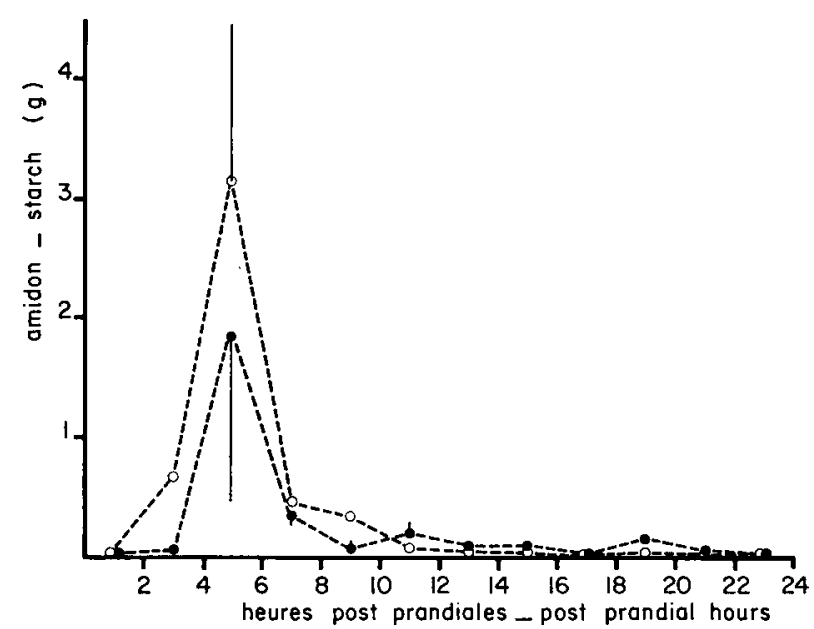

FIG. 5. - Quantités moyennes d'amidon collectées par période de $2 h$ au cours des 24 h consécutives à un repas d'épreuve à base d'amidon de mä̈s (régime à I6 p. Ioo de matières azotées) ingéré à $9 h$.

Dérivation postvalvulaire ( - . - - : : 3 nycthémères du porc $C$; ingéré moyen de matière sèche $886, \mathrm{I} \pm 5,9 \mathrm{~g}$ et d'amidon $600, \mathrm{I} \pm 4,0 \mathrm{~g}$.

Dérivation iléale $(0 \ldots \ldots$ - . - o ) : 3 nycthémères du porc 0 ; ingéré moyen de matière sèche $874,2 \pm 0 \mathrm{~g}$ et d'amidon $592 \pm \mathrm{o} \mathrm{g}$.

Mean amounts of starch collected per 2 -hr period during $2+\mathrm{hr}$ following the intake of a maize starch diet (I6 p. Ioo crude protein) at 9.00 a.m.

- Postvalvular collection (- - - - ) : 3 24-hr-cycles in pig C; mean intake of dry matter $886 . \mathrm{T} \pm 5.9 \mathrm{~g} ;$ of starch $600 . \mathrm{I} \pm 4.0 \mathrm{~g}$.

- Ileal collection ( $\pm 0 \mathrm{~g}$; of starch $592 \pm 0 \mathrm{~g}$.

\section{2. - Digestion de l'amidon}

a) Cinétique de passage de l'amidon (régimes à i6 p. roo de M.A.T.)

L'amidon résiduel d'un repas d'épreuve à base d'amidon de maïs est collecté pour l'essentiel entre la troisième et la huitième heure après le repas; les débits maximaux atteints environ $5 \mathrm{~h}$ après ce dernier (fig. 5) sont de l'ordre de 2 à $3 \mathrm{~g}$ d'amidon collecté en $2 \mathrm{~h}$; ils ne diffèrent pas significativement en fonction des techniques de dérivation. Au total la quantité d'amidon récupérée en 6 ou $24 \mathrm{~h}$, et exprimée en p. Ioo de l'amidon de maïs ingéré, ne diffère pas significativement selon le mode de dérivation (tabl. $2-$ comparaison $\mathbf{I}$ ).

\section{TABLEAU 2}

Quantités cumulées d'amidon recueillies en 6 ou 24 h après le repas d'épreuve et exprimées en p. Ioo des quantités d'amidon ingérées. Résultats comparés selon le site de dérivation post-valvulaire $(D P V)$ ou iléale $(D I)$, selon la nature de l'amidon ingéré, mä̈s ou blé, et selon le taux de matières azotées $(M A T)$ du régime $(16,8$ ou o $p$. IOO). Dans chaque cas sont indiqués la moyenne et l'écart-type de la moyenne, avec entre parenthèses le nombre de données concernées. La signification statistique éventuelle pour chacune des comparaisons (Test de $T$ de Student) est exprimée comme suit: *** $p<0, O O I-* * p<0, O I-* p<0,05-(0,10) p<0,10$. 
Cumuiated quantities of starch collected during 6 or 24 hours after the test meal, as per cent of the starch ingested. Comparisons according to the site of digesta collection, either post valvular (DPV) or ileal $(D I)$, acconding to the kind of starch ingested, maize or wheat, and according to the dietary crude protein (MAT) level (I6 - 8 or o p. IOo). In each case, the mean and standard deviation of the mean are given, with the number of data concerned in brackets. The eventual statistical significance for each comparison (Student's T test) is expressed as follows: *** $p<$ $0,00 I \ldots * * p<0.0 I-* p<0.05-(0.10) p<0.10$.

\begin{tabular}{|c|c|c|c|}
\hline \multirow{2}{*}{$\begin{array}{l}\text { Comparaison } \\
\text { Comparison }\end{array}$} & \multirow{2}{*}{$\begin{array}{l}\text { Situation } \\
\text { Situation }\end{array}$} & \multicolumn{2}{|c|}{$\begin{array}{l}\text { Quantités cumulées d'amidon collecté } \\
\text { en p. Ioo de l'amidon ingéré } \\
\text { Cumulated quantities of starch collected, } \\
\text { as per cent of starch ingested }\end{array}$} \\
\hline & & $\begin{array}{c}\text { Bilan à } 1 \mathrm{a} 6 \mathrm{e} \text { h } \\
\text { post-prandiale } \\
\text { (at the 6th postprandial hour) }\end{array}$ & $\begin{array}{l}\text { Bilan à la } 24^{\mathrm{e}} \mathrm{h} \\
\text { post-prandiale } \\
\text { (at the } 2 \text { th } \\
\text { postprandial hour) }\end{array}$ \\
\hline 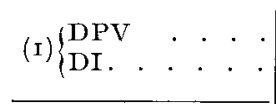 & $\begin{array}{l}\text { Amidon de maïs } \\
(\text { Maize starch }) \\
\text { I6 p. Ioo MAT }\end{array}$ & $\begin{array}{l}0,35 \pm 0, \mathrm{I} 4(n=5) \\
0,45 \pm 0, \mathrm{I} 3(n=5)\end{array}$ & $\begin{array}{l}0,52 \pm 0,13(n=5) \\
0,73 \pm 0, \mathrm{I} 5(n=4)\end{array}$ \\
\hline 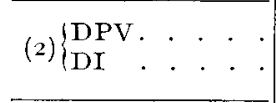 & $\begin{array}{l}\text { Amidon de blé } \\
\text { (Wheat stavch) } \\
\text { i } 6 \text { p. Ioo MAA'T }\end{array}$ & $\begin{array}{l}0,07 \pm 0,01 \quad(n=4) \\
0,08 \pm 0,02(n=5)\end{array}$ & $\begin{array}{l}0,20 \pm 0,02(n=4) \\
0,18 \pm 0,02(n=5)\end{array}$ \\
\hline (3) $\left\{\begin{array}{l}\text { Amidon de blé } \\
\text { (Wheat starch) } \\
\text { Amidon de maïs } \\
\text { (Maize starch) }\end{array}\right.$ & $\begin{array}{llll}\text { DPV } & \cdot & \cdot & \\
\text { I6 } & \text { p. IOO } & \text { MAT }\end{array}$ & $\begin{array}{l}0,07 \pm 0,01 \quad(n=4) \\
0,35 \pm 0,14(n=5)\end{array}$ & $\begin{array}{l}0,20 \pm 0,02(n=5) \\
0,52 \pm 0, \mathrm{I} 3(n=5)^{*}\end{array}$ \\
\hline (4) $\left\{\begin{array}{l}\text { Amidon de blé } \\
\text { (Wheat starch }) \\
\text { Amidon de maîs } \\
(\text { Maize starch })\end{array}\right.$ & I 6 p. IOO MAT & $\begin{array}{l}0,08 \pm 0,02(n=5) \\
0,45 \pm 0,13(n=5)^{*}\end{array}$ & $\begin{array}{l}0,18 \pm 0,02(n=5) \\
0,75 \pm 0,15(n=4)^{* *}\end{array}$ \\
\hline (5) $\left\{\begin{array}{l}\text { Amidon de blé } \\
\text { Wheat starch) } \\
\text { Amidon de maîs } \\
\text { (Maize starch) }\end{array}\right.$ & $\begin{array}{l}\mathrm{DPV}+\mathrm{DI} \\
\mathrm{I} 6 \mathrm{p} . \text { IOO MAT }\end{array}$ & $\begin{array}{l}0,07 \pm 0,01 \quad(n=9) \\
0,4^{\circ} \pm 0,09(n=10)^{* *}\end{array}$ & $\begin{array}{l}0,18 \pm 0,02(n=7) \\
0,63 \pm 0,11(n=8)^{* *}\end{array}$ \\
\hline (6) $\left\{\begin{array}{l}\text { Amidon de blé } \\
\text { (Wheat starch) } \\
\text { Amidon de mais } \\
(\text { Maize starch })\end{array}\right.$ & $\begin{array}{l}\mathrm{DPV}+\mathrm{DI} \\
\text { o p. IOO MAT. }\end{array}$ & $\begin{array}{l}2,69 \pm \mathrm{I}, 55(n=6) \\
5,2 \mathrm{I} \pm 2,46(n=3)\end{array}$ & $\begin{array}{l}6,85 \pm 2,60(n=6) \\
5,50 \pm 2,87(n=4)\end{array}$ \\
\hline 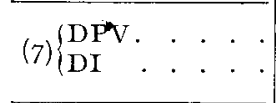 & $\begin{array}{l}\text { Amidons confon- } \\
\text { dus (all starches) } \\
\text { p. roo MAT. }\end{array}$ & 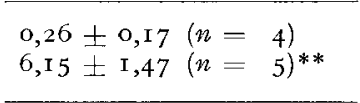 & $\begin{array}{l}3,60 \pm 2,02(n=4) \\
8,12 \pm 2,63(n=6)^{*}\end{array}$ \\
\hline (8) $\left\{\begin{aligned} 16 & \text { p. I0o MAT } \\
8 & \text { p. I I0o MAT }\end{aligned}\right.$ & $\begin{array}{l}\text { Amidons confon- } \\
\text { dus (all starches) } \\
\text { DPV + DI . . . }\end{array}$ & $\begin{array}{l}0,24 \pm 0,06 \quad(n=19) \\
0,17 \pm 0,09(n=4)\end{array}$ & $\begin{array}{l}0,39 \pm 0,07(n=17) \\
0,30 \pm 0,09(n=4)\end{array}$ \\
\hline (9) $\left\{\begin{array}{lll}\text { I6 } & \text { p. I oo MAT } \\
o & \text { p. } & \text { I } 00 \text { MAT }\end{array}\right.$ & $\begin{array}{l}\text { Amidons confon- } \\
\text { dus (all starches) } \\
\text { DPV + DI . . . }\end{array}$ & $\begin{array}{l}0,24 \pm 0,06(n=\text { I9) } \\
3,53 \pm 1,29(n=9)^{* * *}\end{array}$ & $\begin{array}{l}0,39 \pm 0,07 \quad(n=17) \\
6,31 \pm 1,84 \quad(n=10) * * *\end{array}$ \\
\hline (ro) $\left\{\begin{array}{ccc}8 \text { p. } & \text { roo } & \text { MAT } \\
\text { o p. } & \text { I } 00 \text { MAT }\end{array}\right.$ & $\begin{array}{l}\text { Amidons confon- } \\
\text { dus (all stavches) } \\
\text { DPV + DI. . . }\end{array}$ & $\begin{array}{l}0,17 \pm 0,09(n=4) \\
3,53 \pm 1,29(n=9)\end{array}$ & $\begin{aligned} & 0,30 \pm 0,09(n= 4 \\
&(0,10) \\
& 6,31 \pm 1,84(n=10)\end{aligned}$ \\
\hline (I I) $\left\{\begin{array}{c}\text { I6 } 8 \text { p. IоO } \\
\text { MAT } \\
\text { o p. I } 00 \text { MAT }\end{array}\right.$ & $\begin{array}{l}\text { Amidons confon- } \\
\text { dus (all starches) } \\
\text { DPV + DI. . . }\end{array}$ & $\begin{array}{l}0,23 \pm 0,05(n=23) \\
3,53 \pm 1,29(n=9)^{* * *}\end{array}$ & $\begin{array}{l}0,37 \pm 0,06(n=22) \\
6,31 \pm 1,84 \quad(n=10)^{* * *}\end{array}$ \\
\hline
\end{tabular}


Lors d'ingestion d'un amidon de blé, l'amidon résiduel à la fin de l'intestin grêle est collecté entre la troisième et la quinzième heure post prandiale, avec un débit maximum vers la sixième heure (fig. 6) qui n'excède pas 0,3 à $0,5 \mathrm{~g}$ par période de 2 h quelle que soit la technique de dérivation. Au total la quantité d'amidon récupérée en $6 \mathrm{~h}$ ou $24 \mathrm{~h}$, et exprimée en p. Ioo de l'amidon de blé ingéré, ne diffère pas significativement selon le mode de dérivation (tabl. 2 - comparaison 2).

La comparaison des quantités résiduelles d'amidon collectées en 6 ou 24 h, et exprimées en p. Ioo de l'amidon ingéré selon la nature de cet amidon, confirme que les quantités recueillies, sont significativement plus importantes dans le cas du maïs que dans le cas du blé (tab1. 2 - comparaisons 3,4 et 5).

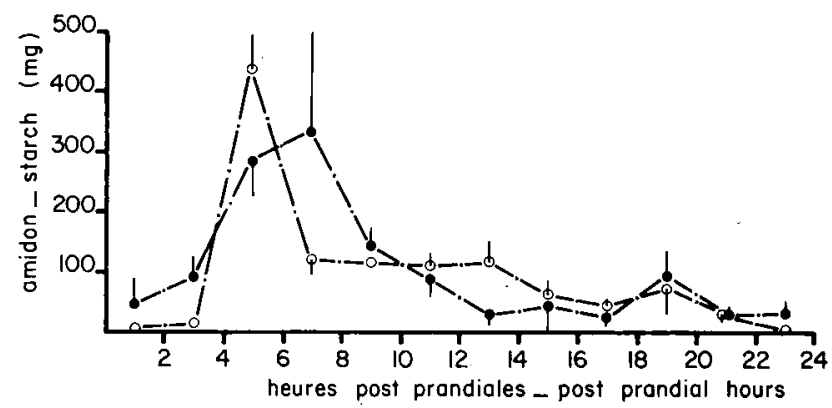

FIG. 6. - Quantités moyennes d'amidon collectées par période de $2 h$ au cours des $24 h$ consécutives à un repas d'épreuve à base d'amidon de blé (régime à 16 p. Ioo de matières azotées) ingéré $\grave{a} g h$.

Dérivation post-valvulaire (૯- - — ) : 3 nycthémères du porc $B$; ingéré moyen de matière sèche $833,8 \pm 20,5 \mathrm{~g}$ et d'amidon $562,7 \pm 13,8 \mathrm{~g}$.

Dérivation iléale ( $0-\cdots-0): 3$ nycthémères du porc $\mathrm{N}$; ingéré moyen de matière sèche $88 \mathrm{I}, \mathrm{x} \pm 5,9 \mathrm{~g}$ et d'amidon $594,6 \pm 4,0 \mathrm{~g}$.

Mean amounts of starch collected per 2 -hr period during 24 hr following the intake of a wheat starch diet ( $16 \mathrm{p}$. Ioo crude protein) at 9.00 a.m.

- Postvalvular collection (- - - ) : 3 24-hr-cycles in pig B; mean intake of dry matter $833.8 \pm 20.5 \mathrm{~g}$; of starch $562.7 \pm 13.8 \mathrm{~g}$.

- Ileal collection ( $5.9 \mathrm{~g} ;$ of starch $594.6 \pm 4.0 \mathrm{~g}$.

b) Influence du taux de M.A.T. du régime (I6, 8, o p. Iоo)

Lors d'ingestion d'un régime protéiprive, et en l'absence de différence significative des quantités résiduelles d'amidon selon la nature de l'amidon ingéré (tabl. 2 - comparaison 6), la comparaison des modes de dérivation peut s'effectuer indépendamment de la nature de l'amidon (fig. 7). L'essentiel de l'amidon résiduel est collecté dans les deux cas entre 2 et $\mathrm{I} 2 \mathrm{~h}$ après le repas, mais avec un débit maximum vers la cinquième heure lors de dérivation iléale, et vers la neuvième heure lors de dérivation post-valvulaire. De plus, le débit maximum est beaucoup plus élevé lors de dérivation iléale. Il en résulte une différence significative, selon le mode de fistulation, des quantités totales d'amidon collectées en 6 ou 24 h après le repas (tabl. 2 - comparaison 7). Ces particularités du débit d'amidon à la fin de l'intestin grêle, lors d'ingestion d'un régime protéiprive conduisent à une différence significative des quantités totales d'amidon collectées en 6 ou 24 h après le repas, par rapport à celles enregistrées pour un régime à 16 p. Ioo de M.A.T. (tabl. 2 - 


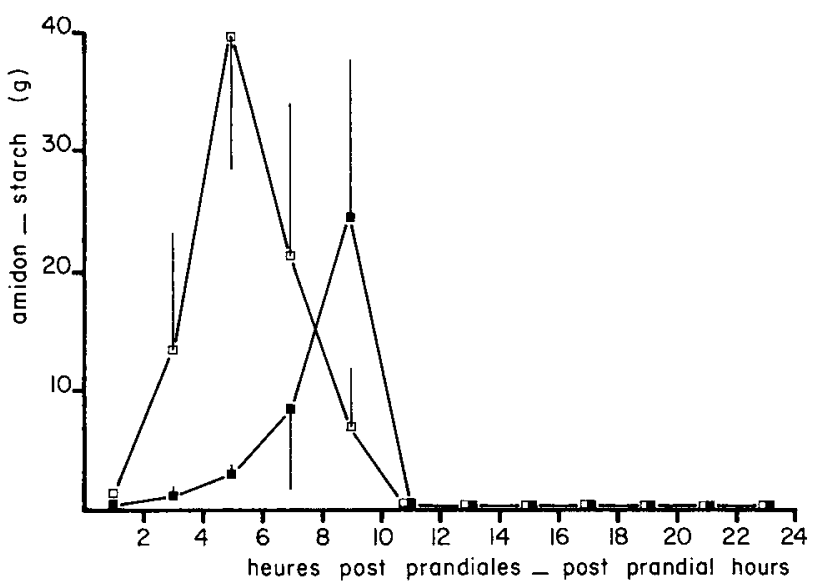

Frg. 7. - Quantités moyennes d'amidon collectées pav période de 2 h au cours des 24 honsécutives à un repas d'épreuve protéiprive ingéré à $9 h$ indépendamment de la natuve de l'amidon ingéré.

Dérivation post-valvulaire (_____. $)$ : 3 nycthémères du porc $B$; ingéré moyen de matière sèche $883,0 \pm 0 \mathrm{~g}$ et d'amidon $79 \mathrm{r}, 9 \pm 0 \mathrm{~g}$.

Dérivation iléale ( $\square-($ ) $): 6$ nycthémères des pores $\mathrm{N}$ et $\mathrm{O}$, ingéré moyen de matière sèche $866,6 \pm 6,2 \mathrm{~g}$ et d'amidon $782,2 \pm 6,5 \mathrm{~g}$.

Mean amounts of starch collected per $2 \mathrm{hr}$ period during $24 \mathrm{hr}$ following the intake of a protein free diet at 9.00 a.m., independent of the type of starch used in the diet.

- Postvalvular collection (-_-_-a) : 324 -hr-cycles in pig B; mean intake of dry matter 883.0 士 $\circ \mathrm{g}$; of starch $791.9 \pm 0 \mathrm{~g}$.

- Ileal collection ( $\square-(-\mathrm{C}): 624$-hr-cycles in pigs $N$ and $O ;$ mean intake of dry matter $866.6 \pm 6.2 \mathrm{~g}$; of starch $782.2 \pm 6.5 \mathrm{~g}$.

comparaisons 9 et II). L'ingestion d'un régime à 8 p. Ioo de M.A.T. ne conduit pas à des bilans significativement différents de ceux obtenus pour des régimes à $\mathrm{I} 6$ ou o p. Ioo de M.A.T. (tab1. 2 - comparaisons 8 et Io).

\section{3. - Interaction du taux de M.A.T. et de la nature de l'amidon du régime}

La concentration des matières azotées dans les digesta collectés (M.A.T. en p. Ioo de la M.S.) évolue de façon très différente, à la suite d'un repas, selon le taux de M.A.T. du régime ingéré, et ce quel que soit le mode de dérivation des digesta (fig. 8A). Pour des régimes à 8 et plus encore à o p. xoo de M.A.T., on enregistre une diminution considérable du pourcentage de M.A.T. dans la M.S. collectée entre la deuxième et la dixième heure après le repas. On note par ailleurs que la régression de la quantité totale de M.S. collectée en 24 h, en fonction du taux de M.A.T. du régime n'est pas significative. Par contre la régression de la quantité totale d'amidon collectée en $24 \mathrm{~h}$, en fonction de ce même taux de M.A.T. du régime est significative $(r=-0,6999-p<0,0 \mathrm{I})$. Cette relation négative entre le taux de M.A.T. đu régime et la quantité d'amidon résiduelle conduit à des variations importantes de la concentration de l'amidon (en p. Ioo de la M.S. récoltée) en fonction du taux azoté đu régime. Une augmentation considérable de la concentration de l'amidon dans la M.S. recueillie est enregistrée en particulier pour le régime protéiprive (fig. $8 \mathrm{~B}$ ). Il existe, pour les régimes à 8 et o p. Ioo de M.A.T. 
une corrélation négative significative entre la concentration de M.A.T. et celle de l'amidon dans la M.S. (tab1. 3). Enfin, on constate, pour ces mêmes régimes pauvres en protéines, que la concentration des M.A.T. dans les digesta est significativement corrélée de façon négative à la quantité de M.S. comme à la quantité d'amidon résiduel, quel que soit le mode de dérivation (tabl. 4).

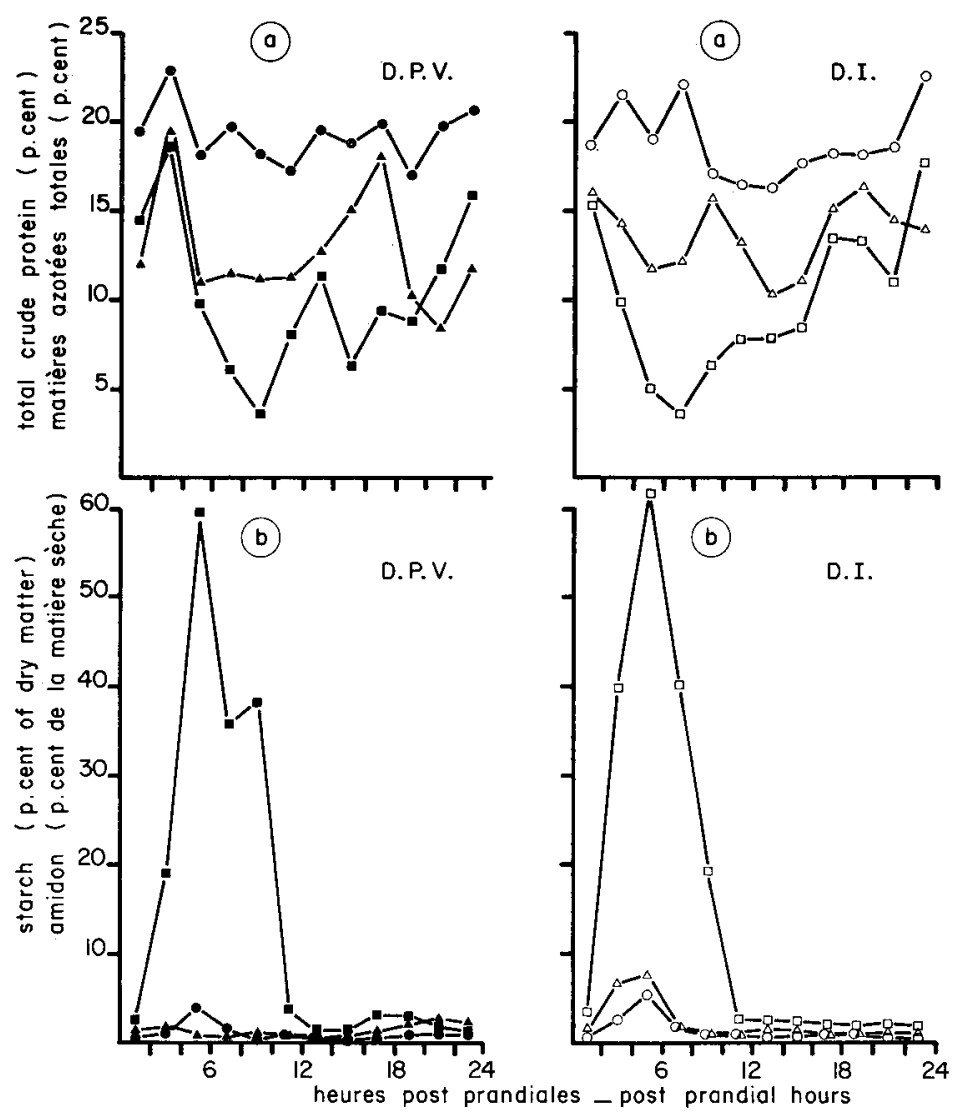

FIG. 8. - Évolution, selon lo taux de matières azoties au végime, do la concontrotion des matièves azotées totales (en a) et de l'amidon (en b), exprimée en p. roo de la matière sèche, au cours des 24 après un repas d'épreuve ingéré à $9 h$, indépendamment de lc nature de l'amidon.

Dérivation post-valvulaire : DPV.

Dérivation iléale : DI. figures.

Les données ici utilisées sont les mêmes, cas par cas, que celles décrites par les précédentes

Post prandial variations, for $24 \mathrm{hr}$ ), according to the dietary crude protein level, in the concentration of cruds protein (a) and starch (b), expressed as per cent of dry matter, following a test meal eaten at 9.00 a.m. independent of the type of starch used in the diet.

Post valvular collection : DPV.

Ileal collection : DI.

The data used are the same as those described in the preceding figures. 
Régression de la concentration des MAT (y-en p. Ioo de la MS) en fonction de la concentration de l'amidon (x-en p. Ioo de la $M S$ ) dans les digesta collectés par dérivation post-valvulaive (DPV) ou par dérivation iléale $(D I)$. Calculs effectués sur la base des données représentatives de chaque collecte de $2 \mathrm{~h}$ tout au long des $24 \mathrm{~h}$.

Regression of the concentration of crude protein ( $y$ as $p$. Too of dry matter) on the concentration of starch ( $x$ as $p$. Ioo of dry matter) in the digesta obtained by either post valvular (DPV) or ileal $(D I)$ collection. Calculations are done on the basis of the representative results from each 2 hr collection during 24 hours.

\begin{tabular}{|c|c|c|c|c|c|}
\hline $\begin{array}{c}\text { Mode } \\
\text { de } \\
\text { fistulation } \\
\text { Mode } \\
\text { of } \\
\text { fistulation }\end{array}$ & $\begin{array}{c}\text { Taux } \\
\text { MAT } \\
(\%) \\
\text { Crude } \\
\text { protein } \\
\text { level }\end{array}$ & $\begin{array}{l}\text { Nombre } \\
\text { de } \\
\text { données } \\
\text { Number } \\
\text { of data }\end{array}$ & $\begin{array}{c}\text { Áquations de régression } \\
\text { Regression equations }\end{array}$ & $\begin{array}{l}\text { Coefficient } \\
\quad \text { de } \\
\text { corrélation } \\
\text { Correlation } \\
\text { coefficient }\end{array}$ & $\begin{array}{l}\text { Signification } \\
\text { Significance }\end{array}$ \\
\hline DPV & $\begin{array}{r}16 \\
8 \\
0\end{array}$ & $\begin{array}{l}88 \\
28 \\
30\end{array}$ & $\begin{array}{l}y=-0,38 x+19,37 \\
y=-2,98 x+14,6 \mathrm{I} \\
y=-0,08 x+10,26\end{array}$ & $\begin{array}{l}-0, \mathrm{I} 642 \\
-0,6023 \\
-0,4686\end{array}$ & $\begin{array}{c}\text { N.S. } \\
p<\text { o, OI } \\
p<0, \text { OI }\end{array}$ \\
\hline DI & $\begin{array}{r}16 \\
8 \\
0\end{array}$ & $\begin{array}{l}85 \\
33 \\
36\end{array}$ & $\begin{array}{l}y=-0,08 x+18,55 \\
y=-0,38 x+14,08 \\
y=-0,12 x+10,95\end{array}$ & $\begin{array}{l}-0,0814 \\
-0,3097 \\
-0,6904\end{array}$ & $\begin{array}{c}\text { N.S. } \\
p<0, \text { IO } \\
p<0, \text { OI }\end{array}$ \\
\hline
\end{tabular}

\section{Discussion}

\section{I. - Evaluation de la digestion et technique de fistulation}

Dans le précédent travail (DARCY, LAPLACE et VILLIERS, I980) il a été observé que les quantités de matière fraîche et de matière sèche collectées en $6 \mathrm{~h}$ sont inférieures d'un tiers et d'un quart respectivement lors de dérivation post valvulaire par rapport à une dérivation iléale. Les digesta font aussi l'objet d'une concentration dans l'iléon puisque leur teneur en matière sèche mesurée lors de collecte post-valvulaire est significativement plus importante que celle enregistrée lors de dérivation iléale. Les résultats complémentaires rapportés dans ce travail montrent que, selon les conditions d'alimentation, certaines différences qualitatives apparaissent ou non en fonction du mode de dérivation.

En ce qui concerne les quantités totales de M.A.T. des contenus iléaux recueillis en 6 ou 24 h, il n'apparaît pas de différence quel que soit le taux de M.A.T. du régime. Mais on note dans le cas de régimes à 8 ou o p. Ioo de M.A.T. une différence de chronologie. En effet, lors de dérivation post-valvulaire, le débit maximum de M.A.T. à la jonction iléo-caeco-colique survient $9 \mathrm{~h}$ après le repas et non $6 \mathrm{~h}$ après ce dernier selon 1'évaluation fournie par dérivation iléale. Pour ce qui concerne l'évaluation de la digestion des M.A.T. (CUD apparent), le mode de dérivation des digesta semble indifférent puisque les mêmes quantités totales de M.A.T. sont obtenues en $24 \mathrm{~h}$ pour un même taux de M.A.T. du régime. Mais l'existence de différences de chronologie revêt ure certaine importance à l'égard de l'évaluation 


\section{TABLEAU 4}

Régression de la concentration des MAT (y-en p. Ioo de la MS) en fonction de la quantité totale de MS ou d'amidon $(x)$ présente dans les digesta collectés par dérivation postvalvulaire $(D P V)$ ou par dérivation iléale $(D I)$. Calculs ettechués sur la base des données représentatives de chaque coilecte de $2 \mathrm{~h}$ tout au long des $24 \mathrm{~h}$.

Regression of the concentration of crude protein ( $y$ as p. Ioo of dry matter) on the total amount of dry matter or starch $(x)$ in the digesta obtained by either post valvular $(D P V)$ or ileal $(D I)$ collection. Calculations are done on the basis of the representative results from each 2 hr collection during 24 hours.

\begin{tabular}{|c|c|c|c|c|c|c|}
\hline & $\begin{array}{l}\text { Mode de } \\
\text { fistulation } \\
\text { Mode of } \\
\text { fistulation }\end{array}$ & $\begin{array}{c}\text { Taux } \\
\text { MAT } \\
(\%) \\
\\
\text { Crude } \\
\text { protein } \\
\text { level }\end{array}$ & $\begin{array}{c}\text { Nombre } \\
\text { de } \\
\text { données } \\
\text { Num- } \\
\text { bev of } \\
\text { data }\end{array}$ & Regression equations & $\begin{array}{c}\text { Coeffi- } \\
\text { cient } \\
\text { de } \\
\text { corré- } \\
\text { lation } \\
\text { Corre- } \\
\text { lation } \\
\text { coeffi- } \\
\text { cient }\end{array}$ & $\begin{array}{l}\text { Signifi- } \\
\text { cation }\end{array}$ \\
\hline \multirow{2}{*}{$\begin{array}{l}\text { Quantité de } \\
\text { M.S. } \\
\text { Amount } \\
\text { of dry } \\
\text { matter }\end{array}$} & DPV . . & $\begin{array}{r}16 \\
8 \\
0\end{array}$ & $\begin{array}{l}97 \\
35 \\
35\end{array}$ & $\begin{array}{l}y=-0,04 x+\mathrm{I} 9,5 \mathrm{I} \\
y=-0,18 x+\mathrm{I} 4,36 \\
y=-0, \mathrm{I} x+\mathrm{I} 2, \mathrm{I} 2\end{array}$ & $\begin{array}{r}-0, \mathrm{I} 3 \mathrm{II} \\
-0,322 \mathrm{I} \\
-0,4499 \\
\end{array}$ & $\begin{array}{c}\text { N.S. } \\
p<\text { o, IO } \\
p<\text { o, OI }\end{array}$ \\
\hline & & $\begin{array}{r}16 \\
8 \\
0\end{array}$ & $\begin{array}{l}92 \\
35 \\
4 \mathrm{I}\end{array}$ & $\begin{array}{l}y=-0,06 x+19,34 \\
y=-0,26 x+15,98 \\
y=-0,14 x+12,00\end{array}$ & $\begin{array}{r}-0,1671 \\
-0,6504 \\
-0,6146\end{array}$ & $\begin{array}{c}\text { N.S. } \\
p<\text { o, OI } \\
p<0 \text {, OI }\end{array}$ \\
\hline \multirow{2}{*}{$\begin{array}{l}\text { Quantité } \\
\text { d'amidon } \\
\text { Amount } \\
\text { of starch }\end{array}$} & DPV & $\begin{array}{r}\mathrm{I} 6 \\
8 \\
\mathrm{o}\end{array}$ & $\begin{array}{l}87 \\
28 \\
27\end{array}$ & $\begin{array}{l}y=3 \cdot 10^{-7} x+18,63 \\
y=-15,48 x+12,95 \\
y=-0,20 x+9,85\end{array}$ & $\begin{array}{r}+0,0003 \\
-0,3816 \\
-0,5536\end{array}$ & $\begin{array}{c}\text { N.S. } \\
p<0,05 \\
p<0, \text { OI }\end{array}$ \\
\hline & DI . . & $\begin{array}{r}\mathrm{I} 6 \\
8 \\
0\end{array}$ & $\begin{array}{l}85 \\
32 \\
36\end{array}$ & $\begin{array}{l}y=-0,8 \mathrm{I} x+\mathrm{I} 8,62 \\
y=-\quad 2,47 x+\mathrm{I} 3,88 \\
y=-\quad 0,16 x+9,95\end{array}$ & $\begin{array}{l}-0,1554 \\
-0,4626 \\
-0,6097\end{array}$ & $\begin{array}{c}\text { N.S. } \\
p<0, \text { OI } \\
p<0, \text { OI }\end{array}$ \\
\hline
\end{tabular}

expérimentale du moment auquel la flore caeco-colique reçoit le plus gros apport de M.A.T. après un repas. Il faut cependant souligner qu'il ne s'agit là que d'une différence relative au moment du débit maximum, mais que la vague post-prandiale de M.A.T. survient dans les mêmes limites de temps.

D'autres différences apparaissent à l'examen comparé des quantités de M.A.T. exprimées en pourcentage des M.A.T. ingérées. Le pourcentage de M.A.T. recueilli lors d'ingestion d'un régime à 8 p. roo de M.A.T. est supérieur à celui enregistré pour un régime à $16 \mathrm{p}$. I oo lors de dérivation iléale. Ceci signifie que, estimée dans ces conditions (dérivation iléale), la digestibilité apparente des M.A.T. est plus faible pour le régime à $8 \mathrm{p}$. Ioo que pour le régime à $\mathrm{I} 6 \mathrm{p}$. Ioo de M.A.T. en accord avec les données classiques (JUST, I 980). Mais cette différence généralement admise n'est pas vérifiée lors de dérivation post-valvulaire. La question se trouve donc posée de la réalité d'une sorte d'homéostasie azotée des contenus quittant l'intestin grêle. Quoiqu'il en soit, l'estimation de la digestibilité apparente des M.A.T. en fonction du taux de M.A.T. du régime s'avère différente selon la technique de fistulation mise en œuvre sous réserve du nombre de données, malgré tout limité, réunies dans ce travail. 
Par ailleurs, on constate que le pourcentage des M.A.T. ingérées recueilli par dérivation iléale est analogue quelle que soit la nature de l'amidon du régime. Par contre, lors de dérivation post valvulaire, ce pourcentage est plus élevé pour le régime à base d'amidon de blé que pour le régime à base d'amidon de maîs, au moins pendant les dix premières heures post-prandiales. Dans ce cas, la différence constatée n'a d'importance qu'à l'égard de la cinétique d'arrivée des matériaux mis à disposition de la flore caeco-colique.

En ce qui concerne l'évaluation de la digestion de l'amidon, des phénomènes analogues sont enregistrés pour les régimes pauvres en protéines. De fait, 1'amidon est digéré en quasi-totalité et aucune différence entre techniques de fistulation ne peut être détectée. Par contre, pour un régime protéiprive on retrouve des différences de chronologie, avec un débit maximum d'amidon à la fois moins élevé et plus tardif lors de dérivation post-valvulaire. On retrouve aussi des quantités totales d'amidon résiduel beaucoup moins importantes lors de dérivation post valvulaire que lors de dérivation iléale. Ceci signifie que l'on sous-estime habituellement dans le cas des régimes pauvres en protéines la digestibilité de l'amidon dans l'intestin grêle.

Au total, on peut retenir de cet inventaire des différences liées à la technique de fistulation qu'il existe d'une part des variations de cinétique de passage, et d'autre part des différences dans les estimations des quantités d'azote et d'amidon quittant l'intestin grêle lors d'ingestion de régimes pauvres en protéines. De fait, les techniques classiques de dérivation iléale conduisent dans ces conditions d'alimentation à sous-estimer la digestibilité apparente de l'azote et de l'amidon en accord avec les réserves formulées par JUST (I980).

\section{2. - Digestion des M.A.T. et production d'azote endogène}

Indépendamment de toute considération de technique de fistulation, la digestion des M.A.T. dans l'intestin grêle peut être envisagée sous deux aspects : digestibilité apparente des M.A.T. de l'aliment, et modification quantitative apportée par l'excrétion d'azote endogène.

Les coefficients d'utilisation digestive apparente (C.U.D.a) des M.A.T', pour les régimes à 16 p. roo de M.A.T. sont de $83, \mathrm{I} 8 \pm 0,3 \mathrm{I}$ p. Ioo lors de formulation à base d'amidon de blé, et de $84,25 \pm 0,50$ lors d'incorporation d'amidon de maîs. Une valeur analogue $(83,69 \pm \mathrm{I}, \mathrm{I} 8)$ est enregistrée pour le régime blé à 8 p. Ioo de M.A.T. Iors de dérivation post valvulaire et sous les réserves exprimées au paragraphe précédent. La comparaison de ces C.U.D.a aux données obtenues par divers auteurs utilisant des préparations classiques de dérivation iléale est malaisée en raison de la diversité de forme de l'apport énergétique (céréales diverses ou amidon purifié) et de nature de la source protéique (céréales elles-mêmes, tourteaux divers ...). Elle reste néanmoins possible, les régimes étant dans la plupart des cas formulés à des taux azotés de I 6 à 19 p. I00, et le mode de dérivation des digesta étant sans conséquence dans l'estimation des C.U.D.a pour des régimes à 16 p. Ioo de M.A.T. Ainsi, lors d'ingestion de blé comme seule source énergétique et azotée, IVAN et FARRELL, (I976) obtiennent des C.U.D.a des M.A.T. de 85,6r pour le blé dur et 80,39 pour le blé tendre. Dans le cas d'un régime à base de maïs grain comportant du tourteau de soja, le C.U.D.a des M.A.T. est de 70,7 pour le grain sec et de 75 à 78 pour du maïs conservé humide selon diverses méthodes (HoLmes, BAYLEY et HoRney, I973). Pour des régimes maïs-soja et maïs-colza les valeurs enregistrées sont respectivement de 79,9 et 67,7 (HoLmes et al., I974); elles sont de 
l'ordre de 78 pour des régimes maïs-arachide et $9 \mathrm{I}$ pour un aliment maïs-caséine (Low, I 979); elles varient entre 66,83 (régime incorporant du soja cru) et 83, I4 (régime comportant du gluten de blé) pour les divers aliments mis en ouvre par ZEBROWSKA (I973). Au total, les C.U.D. a enregistrés dans ce travail s'inscrivent donc dans la plage habituelle de variation en fonction de la diversité de formulation des régimes. Enfin, dans le cas de régimes protéiprives, un C.U.D.a de 28,7 a été fourni par Holmes et al. (I974), le taux réel de M.A.T. de l'aliment étant de 3,65 p. Ioo de la M.S. Cette estimation n'a cependant guère de sens par rapport aux M.A.T. ingérées et n'est pas réalisable pour des aliments réellement protéiprives, soit o,53 p. Ioo de M.A.T. dans la M.S. (ZEBrowskA et al., I975) ou I,25 p. roo de la M.S. dans le cas de nos aliments.

La quantité totale de M.A.T. parvenant à la fin de l'intestin grêle en $24 \mathrm{~h}$ s'est avérée relativement stable, quels que soient le mode de dérivation et la nature de l'amidon, pour un même taux de M.A.T. du régime, soit $23-\mathrm{I} 2$ et $7 \mathrm{~g}$ respectivement pour les aliments formulés à i6-8 et o p. Ioo de M.A.'T. La valeur de $7 \mathrm{~g}$ de M.A.T. collectés en $24 \mathrm{~h}$ pour un régime réellement protéiprive fournit donc l'estimation de la quantité résiduelle d'azote endogène quittant l'intestin grêle. Sur ces bases, la digestibilité réelle des M.A.T. est estimée à 89 p. Ioo et 93 p. Ioo pour les régimes à I 6 et $8 \mathrm{p}$. Ioo de M.A.T. respectivement.

Si l'on formule l'hypothèse d'une digestibilité réelle analogue des M.A.T. endogènes et exogènes, et en adoptant par commodité un coefficient de 90 p. roo, la quantité totale d'endogène serait de l'ordre de $70 \mathrm{~g}$ de M.A.'T. Une telle estimation pour les porcs concernés ( $58 \mathrm{~kg}$ de poids vif moyen) est à rapprocher des valeurs de $70 \mathrm{~g}$ admises pour l'homme de $70 \mathrm{~kg}$ (MUNRo, I 966, in RERAT CorRING et IAPI,ACE, I976) et de $40 \mathrm{~g}$ pour un porc de $50 \mathrm{~kg}$ (ZEBROWSKA et BuRACZEWSKA, I $972, a$ et $b$ ). Sur les $70 \mathrm{~g}$ de M.A.T. endogènes estimées, dont $7 \mathrm{~g}$ sont retrouvés dans la lumière à la fin de l'intestin grêle, $63 \mathrm{~g}$ seraient donc absorbés, ce qui reste compatible avec les 50 g retrouvés dans le sang portal sous forme d'acides aminés (RERAT, CORRING, LAPIACE, I 976) après prélèvement par la paroi intestinale pour son propre métabolisme. Un recoupement n'est pas possible en l'absence d'information quantitative sur le prélèvement de la paroi. Il est cependant plausible que ce dernier soit plus important que les ${ }_{3} 3 \mathrm{~g}$ suggérés par le calcul précédent, compte tenu du renouvellement cellulaire de l'épithélium et de la production des sécrétions intestinales, ce qui conduit à considérer l'évaluation de $70 \mathrm{~g}$ comme une sous estimation.

Si l'on admet, à l'inverse, l'hypothèse d'une digestibilité moins bonne des M.A.T. endogènes far rapport aux M.A.T. exogènes, un coefficient peu inférieur à celui adopté précédemment, 86 au lieu de $90 \mathrm{p}$. Ioo, fournit une estimation de l'endogène total de l'ordre de $50 \mathrm{~g}$ de M.A.T., ce qui est compatible avec l'estimation de ZEBrowska et Buraczewska. (I972a et $b$ ) soit $40 \mathrm{~g}$ pour un porc de $50 \mathrm{~kg}$, mais ne l'est pas avec le bilan d'absorption mentionné par RERAT CoRrIng et LAPLACE (I976) lors d'ingestion d'un régime protéiprive, et donc sans aucun doute largement sous estimé. Enfin le calcul sur la base d'une digestibilité de l'endogène de 60 p. roo environ, résultant des quantités mesurées par ZEBROWSKA et al. (I975) aux niveaux proximal et distal de l'intestin grêle, conduirait à évaluer l'endogène total à environ $47 \mathrm{~g}$ de M.A.T. pour les données de ces auteurs mais à $17,5 \mathrm{~g}$ seulement de M.A.T. sur la base de nos résultats. Cette discordance doit être reliée au fait que les canules "distales » de ZEBROWSKA et al. (I 975) sont situées en moyenne à près de $3 \mathrm{~m}$ en amont de la jonction iléo-caeco-colique, ce qui conduit du reste à collecter des quantités de digesta doubles de celles que nous enregistrons par dérivation post-valvulaire. L'évaluation aberrante de $17,5 \mathrm{~g}$ de M.A.T. endogènes, 
fondée sur nos résultats en leur appliquant le coefficient de 60 p. Ioo calculé d'après ZEBROWSKA et al. (I975) conduit donc à rejeter cette estimation de la digestibilité de l'endogène, tout en soulignant l'importance du site de dérivation des digesta.

Au total notre évaluation des M.A.T. endogènes à $70 \mathrm{~g}$ environ pour une digestibilité de 90 p. Ioo s'avère en définitive seule compatible avec le bilan d'absorption azotée en régime protéiprive (RERAT, CORRING, LAPLACE, I976) et ce que 1'on sait de la production de cet endogène puisque à elle seule la sécrétion pancréatique d'un porc de $50 \mathrm{~kg}$ représente $\mathrm{I} 8 \mathrm{~g}$ de M.A.T. en $24 \mathrm{~h}$ (CoRRING, I975). Néanmoins cette valeur de $70 \mathrm{~g}$ est certainement sous estimée si l'on tient compte des proportions relatives entre les différentes sources d'endogène (NASSET, Ig65; FAUCONNEAU et MICHEL, I970) d'une part et de la quantité apportée par la seule secrétion pancréatique d'autre part. Il suffirait au demeurant que la digestibilité de l'endogène soit un peu supérieure à notre première hypothèse, 93 au lieu de $90 \mathrm{p}$. I0o, pour que les M.A.T. endogènes représentent au total quelques roo $\mathrm{g}$ dont 7 seulement seraient retrouvés à la fin de l'intestin grêle.

\section{3. - Digestion de l'amidon}

D'un point de vue cinétique, et abstraction faite du mode de fistulation, le passage de l'essentiel de l'amidon résiduel à la fin de l'intestin grêle s'effectue sur une période beaucoup plus longue dans le cas des régimes ( 6 p. Ioo de M.A.T.) à base d'amidon de blé que pour les régimes à base d'amidon de maïs (troisième à quinzième au lieu de huitième heure postprandiale). L e débit maximum d'amidon est approximativement Io fois plus élevé dans le cas de 1'amidon de maîs. En dépit de la moindre durée pendant laquelle est enregistré un débit significatif d'amidon dans le cas d'ingestion d'amidon de maïs, c'est pour ce dernier que l'on collecte au total les plus fortes quantités d'amidon résiduel à la fin de l'intestin grêle.

Le C.U.D.a de 1'amidon correspondant est de 99,4 p. roo dans le cas de notre régime à base d'amidon de maïs purifié, soit une valeur identique à celle observée par IVAN et FARRELL (I976) pour un régime analogue, mais supérieure aux valeurs (94,0 à 98,I p. I oo) enregistrées par Hol,Mes et al. (I974) pour du mais-céréale entière soumis à divers modes de conservation. Cette différence peut être attribuée à la forme de présentation de 1'amidon : inclus dans la farine de céréale ou purifié. L.e C.U.D.a de 1'amidon enregistré pour notre régime à base d'amidon de blé purifié (99,8 p. Ioo) est supérieur à celui obtenu pour le maïs $(99,4 \mathrm{p}$. Ioo). Un écart analogue est enregistré par IVAN et FARRELL (I976) pour leurs deux régimes à base de blé et leur régime de référence à base d'amidon de maïs purifié, soit 99,4 à 99,7 p. Ioo. Il semble donc que, quelle que soit la forme d'apport de l'amidon de blé, céréale broyée ou amidon purifié, sa digestibilité apparente soit meilleure que celle du maïs. Il est plausible que cette différence résulte du temps de séjour globalement plus long de l'amidon de blé dans l'intestin grêle, puisque le passage de ce qu'il en reste est beaucoup plus étalé dans le temps.

Abstraction faite de cette influence de la nature de l'amidon ingéré, il apparaît que la digestibilité apparente de l'amidon est abaissée d'environ $5 \mathrm{p}$. Ioo dans le cas d'un régime protéiprive : la quantité relative d'amidon résiduel à la fin de l'intestin grêle est en effet $I 7$ fois plus importante pour un régime protéiprive que pour les régimes azotés.

La concordance des différents éléments concernant les concentrations de 
M.A.T. et d'amidon dans les digesta collectés et exprimés dans la figure 8 et les tableaux 3 et 4 conduit à retenir les points suivants :

(i) plus le taux de M.A.T. du régime est faible, plus basse est la concentration des M.A.T. dans la matière sèche recueillie;

(ii) plus le taux de M.A.T. du régime est faible, plus forte est la concentration de l'amidon dans la matière sèche recueillie;

(iii) plus faible est la concentration des M.A.T. dans la matière sèche des digesta, plus forte est celle de l'amidon et plus élevée aussi est la quantité totale d'amidon résiduel.

Ceci revient à dire que plus faible est le taux de M.A.T. du régime, plus importante est la quantité d'amidon résiduel (corrélation négative significative). En d'autres termes, en-dessous d'un niveau optimum de protéines dans la ration, la digestion de 1'amidon s'effectue d'autant moins bien que ce taux est plus bas. Le fait qu'une corrélation très significative puisse être calculée dans tous les cas entre la quantité de M.S. et la quantité d'amidon recueillies en 24 h à la fin de l'intestin grêle ne doit pas conduire à conclure abusivement à l'existence d'une corrélation négative entre taux de M.A.T. du régime et quantité de M.S. En effet, une telle relation n'est pas vérifiée, ce qui est cohérent avec le fait que, au total en $24 \mathrm{~h}$, l'amidon représente au plus en moyenne 2 p. Ioo de la M.S. franchissant la jonction ileo-caeco-colique.

\section{Conclusions}

Plusieurs différences concernant la cinétique de passage ou l'estimation de la digestibilité à la fin de l'intestin grêle sont mises en évidence en fonction de la technique de fistulation :

- Pour les régimes pauvres en protéines, le débit maximum de M.A.T. est enregistré environ $3 \mathrm{~h}$ plus tard lors de dérivation post-valvulaire.

- Cependant pour un même taux azoté, la quantité de M.A.T. quittant 1'intestin grêle en 24 h et l'évaluation de la digestibilité des M.A.T. alimentaires ne sont pas différentes.

- La notion de digestibilité apparente plus faible des M.A.T., pour les régimes pauvres en protéines, est vérifiée lors de dérivation iléale, mais elle ne l'est pas lors de dérivation post valvulaire (analogie des C.U.D.a pour des régimes à 8 et I6 p. roo de M.A.T.). Les C.U.D.a des M.A.T. enregistrés pour les régimes à I6 p. roo de protéines sont analogues à ceux rapportés dans la littérature.

- Le pourcentage des M.A.T. ingérées recueilli en $6 \mathrm{~h}$ après le repas est plus élevé pour un régime à base d'amidon de blé que pour un régime à base d'amidon de mais; cette influence de la nature de 1'amidon n'est détectée que lors de dérivation post-valvulaire.

- Dans le cas particulier des régimes protéiprives, le débit maximum d'amidon à la fin de l'intestin grêle est moindre et survient plus tard lors de dérivation post-valvulaire; le C.U.D.a de 1'amidon est, dans ce même cas, sous-estimé lors de dérivation iléale.

Indépendamment de ces points particuliers liés à la technique de fistulation, on retient que :

- la quantité d'azote endogène produite en 24 h est estimée à $70 \mathrm{~g}$ au moins pour des porcs de $60 \mathrm{~kg}$ environ dans nos conditions expérimentales; 
- la digestibilité de l'amidon de blé est supérieure à celle de l'amidon de maïs, particularité qui peut être reliée au plus grand étalement dans le temps du passage de 1'amidon de blé résiduel à la fin de l'intestin grêle;

- quelle que soit la nature de l'amidon du régime, sa digestion est réduite dans le cas d'un régime protéiprive.

Accepté pour publication en juillet 1980.

\section{Summary}

Digestion in the small intestine of the pig. 3. Kinetics of passage of starch and crude protein in the ileum according to the mode of fistulation, the type of starch and protein level of the diet

Six castrated Large-White pigs with a live-weight range of 47-64 kg were used to compare the passage of starch and crude protein at the end of the small intestine, according to the mode of fistulation used, either ileo-caecal or post-valvular ileo-colic. The animals received one daily meal including a semi-synthetic feed based on purified starch (maize or wheat, 70 per cent of the dry matter) and fish-meal ( 6,8 or $o$ p. Ioo total crude protein). The digesta were collected every 2 hours over the whole 24 -hr-cycle. The amounts of crude protein $(\mathrm{N} \times 6,25)$ and the amounts of starch (glucose and all its $\alpha$ derivatives) were measured in the digesta collected.

In addition to previously reported peculiarities (DARCY, LAPLACE, VILLIERS, I980) differences due to the mode of fistulation were recorded. Some of them concerned the kinetics of passage, in the case of low protein diets, as: delayed maximum flow-rate of crude protein and lower and delayed maximum flow rate of starch in the case of post-valvular collection. The lower apparent digestıbility of crude protein after intake of low protein diets was confirmed by ileal collection but failed to appear in the case of post-valvular collection. The influence of the type of starch on crude protein digestibility was evidenced only by post-valvular collection.

Independently of these consequencies of the mode of fistulation, it appeared that: (i) the amount of endogenous nitrogen produced daily could be estimated at $7^{\circ} \mathrm{g}$ at least; (ii) the apparent digestibility of wheat starch is better than that of maize starch; (iii) digestion of starch is reduced by 5 per cent in the case of protein free diets.

\section{Références bibliographiques}

CORRING $\uparrow$., I975. Apport de protéines d'origine endogène par la sécrétion du pancréas exocrine chez le porc. Ann. Biol. anim. Bioch. Biophys., 15, I I5-I I 8.

Cuber J. C., LAPLACE J. P., r979. Évacuation gastrique de l'amidon et de l'azote d'un régime semi-purifié à base d'amidon de mais chez le porc. Ann. Zootech., 28, I73-I84.

Darcy B., Laplace J. P., Villifrs P. A., I980. Digestion dans l'intestin grêle chez le Porc. 2) Cinétique comparée de passage des digesta selon le mode de fistulation, iléo-caecale ou iléo-colique postvalvulaire, dans diverses conditions d'alimentation. Ann. Zootech., 29, I47I 77 .

DERBLOM H., JOHANSSON H., NYIANDER G., I966. A simple method of recording quantitatively certain gastro-intestinal motility functions in the rat. Acta chir. Scand., 132, I54-I65.

FAUCONnEAU G., Micher M. C., I970. The role of the gastro-intestinal tract in the regulation of protein metabolism, chap. 37 , pp. $48 \mathrm{I}-522$, in MUNRo H. N., Mammaliani Protein Metabolism, Acad. Press. Inc., N.Y.

Holmes J. H. G., BAyley H. S., HORNEY F. D., I973. Digestion and absorption of dry and high moisture maize diets in the small and large intestine of the pig. Brit. $J$. Nutr., 30, 401-410.

Holmes J. H. G., BAYLFY H. S., LEAdBEATER P. A., HoRnev F. D., I974. Digestion of protein in small and large intestine of the pig. Br. J. Nutr., 32, 479-489.

IVAN M., FARRELI, D. J., I976. Nutritional evaluation of wheat. 5) Disappearance of components in digesta of pigs prepared with two re-entrant cannulae. Anim. Prod., 23, IIr-II9. 
Juan R., Pecking A., Najean Y., Bernier J. J., 1979. Fitude de la progression d'un repas dans l'intestin grêle de l'homme par une méthode scintigraphique. Gastroenterol. Clin. Biol., 3, $755^{-7} 62$.

JUst A., I980. Ileal digestibility of protein. Applied aspects. pp. 66-75, In : Low A. G., PARTRIDGE I. G., Current concepts of digestion and absorption in the pig. N.I.R.D., Reading (U.K.)

Low A. G., 1979. Studies on digestion and absorption in the intestines of growing pigs. 5) Measurements of the flow of nitrogen. Br. $J$. Nutr., 41, 137-146.

NASSET E. S., 1965. Role of the digestive system in protein metabolism. Fed. Proc. 24, 953-958.

PURdon R. A., BASS P., I 973. Gastric and intestinal transit in rats measured by a radioactive test meal. Gastroenterology, 64, 962-967.

Rerat A., Corring T., Laplace J. P., i976. Protein digestion and absorption, pp. 97-I 38, in Cole D. J. A., Boorman K. N., Buttery P. J., Lewis D., Neale R. J., Swan H., Protein Metabolism and Nutrition, Butterworths, Londres.

Wright S., I952. Applied Physiology, chap. 7 Digestion, 774-834, Oxford Medical Publications, 9th Ed., Oxford University Press, Londres.

ZEBROWSKA T., BURACZEWSKA I., I 972a. Effect of proportion of protein in the diet on digestion in the small intestine of pigs. I. Amount and composition of digesta (Polish). Rocz. Nauk Roln., 94 (B), 8I-96.

ZEBROWSKA T., BURACZEWSKA L, , 1972 $b$. Efffect of proportion of protein in the diet on digestion in the small intestine of pigs. 2. Rate of digestion of protein and absorption of amino-acids (Polish). Rocz. Nauk. Roln., 94 (B), 97-109.

ZEBROWSkA T., I973. Influence of dietary protein source on the rate of digestion in the small intestine of pigs. I. Amount and composition of digesta. Rocz. Nauk. Roln., 95 B, II5-I33.

Zebrowska T., Buraczewska L., Buraczewski S., Horszczaruk F., 1975. Digestion and absorption in the small intestine of pigs. I) Digestion and absorption of dry matter and nitrogen. Rocz. Nauk. Roln., 96 B, 79-9o. 